\title{
US intensity and nonreinforcement technique in eyelid conditioning
}

FRED A. MINNIGERODE and DANIEL C. O'CONNELL, Department of Psychology, Saint Louis University, St. Louis, Missouri 63103

Forty-four Ss received 80 conditioning trials with $50 \%$ reinforcement. US intensity (l vs 2 psi) and nonreinforcement technique (US-omit vs US-delay) were factorially manipulated. US-delay consisted of a $5000 \mathrm{msec} I S \mathrm{SI}$. Two independent criteria identified CRs. More CRs occurred after reinforced trials than after nonreinforced trials; US-delay produced better conditioning than US-omit. Although the two criteria yielded similar results, the importance of appropriate criteria in identifying the $C R$ was recognized.

Since either omission or delay of the US defines nonreinforcement, performance in eyelid conditioning under intermittent reinforcement can be a function of nonreinforcement technique. Moore \& Gormezano (1963) demonstrated that US-omit produced better conditioning than US-delay across several reinforcement schedules. They suggested that a response in competition with the CR was conditioned to the delayed US; consequently, fewer criterion CRs occurred under US-delay. Homzie (1967) showed that the CR could be displaced in time towards the delayed US. When the interstimulus interval (ISI) was shifted from $500 \mathrm{msec}$ to 600-2500 msec, CR latency lengthened proportionately. With a $1000 \mathrm{msec}$ ISI responding persisted at a reduced rate. These results indicate that the usual US-delay, $1000 \mathrm{msec}$, yields fewer criterion CRs than US-omit because of either competing responses or CR displacement. To minimize the probability of either event, the present experiment employed a $5000 \mathrm{msec}$ ISI on US-delay trials.

Comparison of these nonreinforcement techniques after shifts from continuous to intermittent reinforcement (Ross, 1959) revealed greater overall performance decrement under US-omit than under US-delay. Performance differences were attributed to differential response decrement after nonreinforced trials, with greater response decrement after US-omit trials than after US-delay trials. During acquisition US-delay might produce better conditioning than US-omit due to greater response decrement after US-omit than after US-delay trials.

Ross \& Spence (1960) reported that conditioning under intermittent reinforcement was an increasing function of US intensity. With intermittent reinforcement Spence (Ross \& Spence, 1960) typically employed US-delay nonreinforcement. However, Runquist (1963) and Boice \& Boice (1966), with US-omit nonreinforcement, demonstrated an inverse relationship between US intensity and performance. Runquist (1963) did obtain evidence of possible confounding due to Taylor MAS scores. Although Boice \& Boice (1966) had predicted differential response decrement after nonreinforced trials as a function of US intensity, their hypothesis was not confirmed.

The present experiment investigated the effects of two US intensities and two nonreinforcement techniques upon eyelid conditioning under $50 \%$ reinforcement. It was expected that US-delay would produce better conditioning than US-omit due to greater response decrement after US-omit trials than after US-delay trials. Previous research has also suggested that with US-omit nonreinforcement a weak US intensity produces better conditioning than a strong US intensity.

\section{Subjects and Design}

\section{METHOD}

The Ss were 44 volunteers, 24 men and 20 women, from Saint Louis University. Assignment to one of four experimental conditions was random except that the ratio of men to women in each condition was 6:5. The experimental conditions according to their combination of US intensity and nonreinforcement technique were designated: Strong-Omit, Strong-Delay, WeakOmit, Weak-Delay. The groups were comparable, $F(3,40)=.641$, $p>.25$, on Taylor MAS scores. A 2 by 2 by 2 by 4 factorial design was employed with US intensity ( 1 vs 2 psi) and nonreinforcement technique (US-omit vs US-delay) being between-S variables. Manner of CR occurrence (after reinforced trial vs nonreinforced trial) and stage of conditioning (four blocks of 20 trials) were within-S variables.

Apparatus

The CS, a 1000 cps tone, $40 \mathrm{~dB}$ above threshold, had a 100 msec duration. The tone, generated by a Lafayette Radio Model TE-22, was presented through earphones against a continuous 15 $\mathrm{dB}$ white noise background. The US, a $100 \mathrm{msec}$ air puff, was automatically released by a silent solenoid valve and was presented to the S's right eye through an orifice positioned 1 in. from his cornea. On US-delay trials ISI was $5000 \mathrm{msec}$. Onset and of fset of stimuli were controlled by Hunter timers. Eyelid movements were recorded by means of a plastic "eyelash," attached to S's right eyelid. The "eyelash" was connected to a microtorque potentiometer, which led to a Brush Model B1-202. Onsets of stimuli were also recorded.

Procedure

The $S$ was seated with his back towards $E$ and was instructed to keep his head steady throughout the experiment, to take ordinary care of his eyes, and not to keep his eyes closed. The Ss received 80 conditioning trials under a $50 \%$ reinforcement schedule. Order of reinforcement and nonreinforcement was random except that each block of 20 trials contained 10 reinforced and 10 nonreinforced trials. The intertrial interval varied from $15-25 \mathrm{sec}$ and averaged 20 sec.

Measurement of Response

Two independent criteria were used to identify CRs. Spence \& Ross (1959), employing a ready signal during conditioning, developed primarily a latency criterion. They identified CRs as occurring $200-500 \mathrm{msec}$ after CS onset. Runquist (1963) and Boice \& Boice (1966), both reporting controversial results, used this criterion without having presented a ready signal. In the present experiment a latency criterion identified responses occurring 100-500 msec after CS onset as CRs if they exceeded a 1 mm closure.

Hartman \& Grant (1961) demonstrated the inadequacy of a simple latency criterion when a ready signal was not employed. They suggested a criterion based upon relative slope. Goodrich (1966) proposed the simultaneous use of a $20 \%$ slope and 435 msec latency criterion. He defined slope by the maximum excursion of the inkwriter prior to $50 \mathrm{msec}$ after initiation of the response. The excursion measure for each response was expressed as a percentage of that S's mean closure on the first five URs. In the present experiment a slope-latency criterion identified responses as CRs if they occurred with less than $20 \%$ slope in the 435-500 msec interval following CS onset.

\section{RESULTS}

For each experimental condition the number of CRs, recorded with the latency criterion, is shown in Fig. 1, plotted as a function of blocks of 20 trials. The main effects of US Intensity and Nonreinforcement Technique were not significant. Manner of CR Occurrence produced a significant main effect, $F(1,280)=45.01$, $\mathrm{p}<.01$, with more $\mathrm{CRs}$ recorded after reinforced than after nonreinforced trials. Stage of Conditioning produced a significant main effect, $F(3,280)=14.19, p<.01$, with the latter stages of conditioning producing higher levels of responding. Finally, the US Intensity by Nonreinforcement Technique by Stage of Conditioning interaction was significant, $F(3,280)=2.88, p<.05$. Under US-omit, US intensity and performance were inversely related during the initial stages of conditioning and were directly related in the later stages; under US-delay, the direct relationship appeared in the initial stages, while the inverse relationship occurred later.

For each experimental condition the number of CRs, recorded with the slope-latency criterion, is shown in Fig. 2. As in the previous analysis, neither US Intensity nor Nonreinforcement 


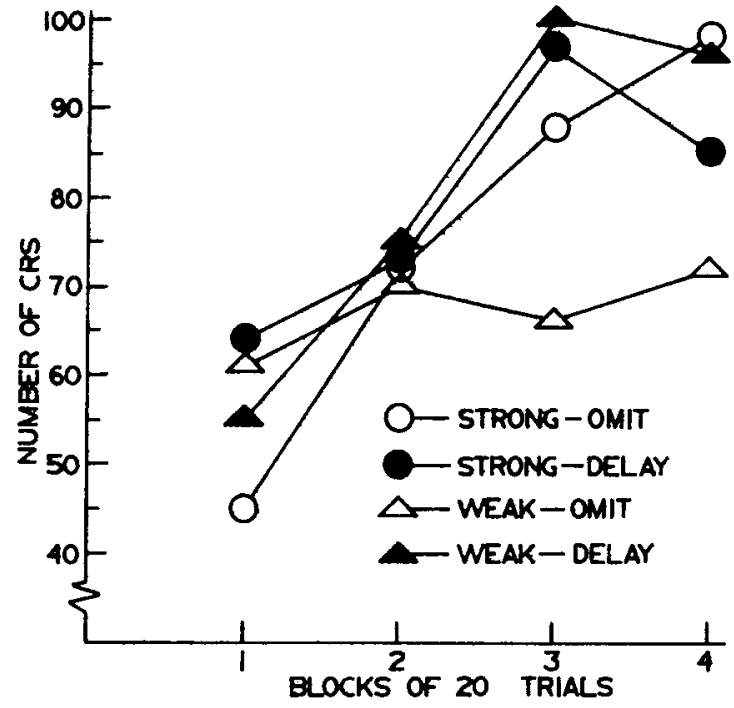

Fig. 1. Number of CRs identified by the latency criterion with each block of 20 trials containing 10 reinforced and 10 nonreinforced trials.

Technique produced significant main effects; however, the main effects of Manner of CR Occurrence, $F(1,280)=35.35, p<.01$, and Stage of Conditioning, $F(3,280)=14.00, p<.01$, were significant. Finally, the Nonreinforcement Technique by Stage of Conditioning interaction was significant, $\mathrm{F}(3,280)=2.81, \mathrm{p}<.05$, with US-delay producing higher levels of responding across trials than US-omit.

A Product-Moment correlation of $+.53(\mathrm{p}<.01)$ was obtained between the number of responses recorded for each $S$ by the two criteria. This suggested considerable overlap between the two criteria; however, that the correlation was not +1.00 is clear from a comparison of Figs. 1 and 2.

\section{DISCUSSION}

That US Intensity produced no main performance effect was not without precedent. Spence \& Taylor (1951) employed comparable intensities (0.6 vs $2.0 \mathrm{psi})$ and did not obtain reliable performance differences. This suggested that these intensities were not sufficiently different to produce significantly different drive levels. The failure to obtain differential response decrement after nonreinforced trials as a function of US intensity was consistent with the results of Boice \& Boice (1966).

Nonreinforcement Technique did not produce significant main effects; but with the data identified by the slope-latency criterion, US-delay yielded significantly higher levels of responding across trials than US-omit. These results, contrary to those of Moore \& Gormezano (1963), suggest that competing responses and/or CR displacement under US-delay can be minimized with an extended ISI on nonreinforced trials. Contrary to expectations, differential response decrement did not occur after nonreinforced trials as a function of nonreinforcement technique.

The +.53 correlation between the two criteria revealed that the criteria, though functionally similar, were not functionally identical. The US Intensity by Nonreinforcement Technique by Stage of Conditioning interaction in the data supplied by the latency criterion had no counterpart in the other set of data. Boice \& Boice (1966), using a similar criterion, demonstrated an inverse relationship between US intensity and performance under $50 \%$ reinforcement with US-omit nonreinforcement. In the present experiment under US-omit, this inverse relationship appeared during the initial stages of conditioning and a direct relationship appeared in the later stages; but under US-delay the direct

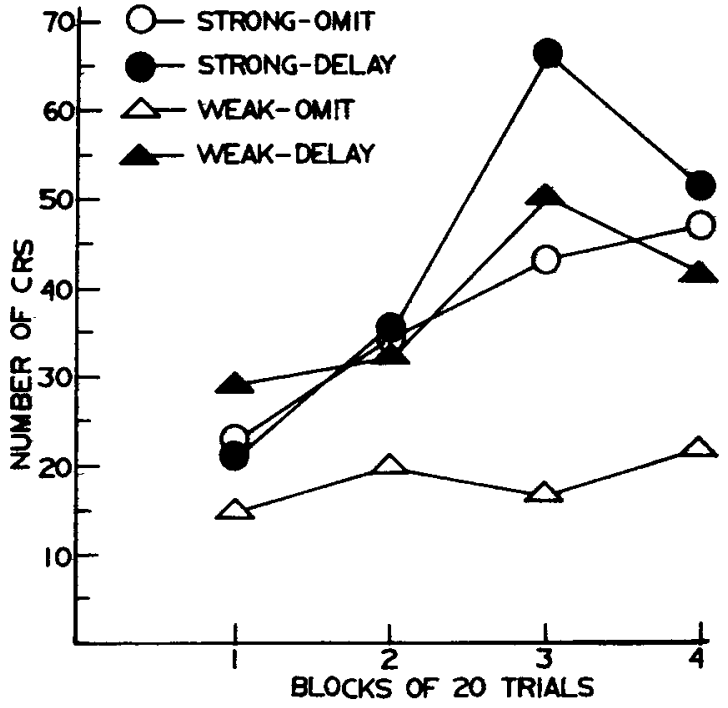

Fig. 2. Number of CRs identified by the slope-latency criterion with each block of 20 trials containing 10 reinforced and 10 nonreinforced trials.

relationship appeared initially, the inverse later. The criterion employed in these experiments to identify the CR may have been the reason for these inconsistent data. The latency criterion in the present experiment and Boice and Boice's criterion were inappropriate. Since both experiments employed no ready signal, the more appropriate criterion would have been slope, not latency. The slope-latency criterion, more appropriate for the present methodology, provided data, which were more consistent with previous findings.

It becomes evident that choice of criteria in identifying CRs is quite critical if reliable results are to be obtained. In particular, the characteristics of the $C R$ and the conditions determining its temporal occurrence warrant further investigation.

\section{REFERENCES}

BOICE, R., \& BOICE, C. An inverse effect of UCS intensity upon partially reinforced eyelid conditioning. Psychonomic Science, 1966, 5, 69-70.

GOODRICH, K. P. Experimental analysis of response slope and latency as criteria for characterizing voluntary and nonvoluntary responses in eyeblink conditioning. Psychological Monographs, 1966, 80, 1-34.

HOMZIE, M. J. Performance in classical eyelid conditioning as a function of the lengthening of the CS.UCS interval. Psychonomic Science, 1967, 7, 211-212.

MOORE, J. W., \& GORMEZANO, 1. Effects of omitted versus delayed UCS on classical eyelid conditioning under partial reinforcement. Journal of Experimental Psychology, 1963, 65, 248-257.

ROSS, L. E. The decremental effects of partial reinforcement during acquisition of the conditioned eyelid response. Journal of Experimental Psychology, 1959, 57, 74-82.

ROSS, L. E., \& SPENCE, K. W. Eyelid conditioning performance under partial reinforcement as a function of UCS intensity. Journal of Experimental Psychology, 1960, 59, 379-382.

RUNQUIST, W. N. Performance in eyelid conditioning following changes in reinforcement schedule. Journal of Experimental Psychology, 1963, 65, 617-618.

SPENCE, K. W., \& ROSS, L. E. A methodological study of the form and latency of the eyelid responses in conditioning. Journal of Experimental Psychology, 1959, 58, 376-381.

SPENCE, K. W., \& TAYLOR, J. A. Anxiety and strength of UCS as determiners of the amount of eyelid conditioning. Joumal of Experimental Psychology, 1951, 42, 183-188. 